\title{
Refunding Emission Payments: Output-Based Versus Expenditure-Based Refunding
}

\author{
Cathrine Hagem ${ }^{1}$ (D) $\cdot$ Michael Hoel $^{2} \cdot$ Thomas Sterner $^{3}$
}

Accepted: 16 September 2020 / Published online: 25 September 2020

(c) The Author(s) 2020

\begin{abstract}
We analyse two mechanism designs for refunding emission payments to polluting firms: output-based refunding (OBR) and expenditure-based refunding (EBR). In both instruments, emission fees are returned to the polluting industry, typically making the policy more politically acceptable than a standard tax. The crucial difference between OBR and EBR is that the fees are refunded in proportion to output in the former but in proportion to the firms' expenditure on abatement technology equipment in the latter. To achieve the same abatement target as a standard tax, the fee level in the OBR design is higher, whereas the fee level in the EBR design is lower. The use of OBR and EBR may lead to large differences in the distribution of output and costs across firms. Both designs imply a cost-ineffective provision of abatement, as firms put relatively too much effort into reducing emissions through abatement technology compared with reducing output. However, a standard tax may be politically infeasible and maintaining output may be seen as a political advantage by policymakers if they seek to avoid activity reduction in the regulated sector.
\end{abstract}

Keywords Refunded charge · Output-based · Expenditure-based · NOx · Tax subsidy · Policy design

JEL Classification Q28 - Q25 · H23

\section{Introduction}

It is well known that a uniform tax, levied on all sources of emissions, is a cost-effective instrument to reduce uniformly dispersed emissions. An ideal such tax is referred to as a Pigouvian tax. However, environmental taxes in practice tend to be lower than required to correct for environmental externalities. One reason is that high taxes reduce domestic competitiveness, leading to firm closures and job losses. Furthermore, for transboundary

Cathrine Hagem

cah@ssb.no

1 Research Department, Statistics Norway, PO Box 2633, St. Hanshaugen, 0131 Oslo, Norway

2 Department of Economics, University of Oslo, PO Box 1095, Blindern, 0317 Oslo, Norway

3 Department of Economics, University of Gothenburg, PO Box 640, 40530 Gothenburg, Sweden 
pollutants, such as greenhouse gases, the welfare effect of reduced domestic emissions may be partly offset by increased production and emissions abroad (carbon leakage), see Hoel (1991). Moreover, powerful lobbies may overstate these and other arguments and thus make a cost-effective tax regime politically infeasible. All in all, the inability to levy sufficiently high environmental taxes is a problem for the design of environmental policy. Currently we see many proposals for "fee and dividend" schemes through which climate taxes would be returned as checks to the population to make them politically more palatable. ${ }^{1}$ Our study concerns something slightly different since we look at refunding to industrial emitters but some of the lessons learnt may still be relevant also to this larger debate on rebating.

With tradable emission permits, which is the quantity-based alternative to an environmental tax, the problem can be alleviated by allocating permits for free. Pezzey (1992) is an early reference pointing out the symmetry between price and quantity type instruments with respect to output allocation or refunding. Hepburn et al. (2013) and Nicolai (2015) analyze allocation rules that ensure profit-neutrality. Free allocation of permits reduces the revenue raised, yet holds the permit price constant (to the first order); hence the abatement incentive and economic efficiency are, in principle, unaffected. However, a different political problem is created: how to allocate free permits. The same problem applies to the price-based equivalent of free tradable permits-giving away tradable thresholds for the emissions tax (Pezzey 2003) - although this option is little known by policymakers and hence undeveloped institutionally and legally.

An alternative way to make emissions taxes more politically feasible is to earmark the tax revenues for some environmental purpose. Some people even see the use of the tax revenues as the environmental purpose of the tax but in reality the determinants of an optimal tax level are more complex, (see Sterner and Coria 2012, pp. 187-191). Kallbekken et al. (2011) show that recycling the revenues to more narrowly targeted groups seems to increase support for taxation. Various ways of refunding the tax revenue can lessen political resistance to the tax. For example, they can be refunded directly to taxpayers, as is done with oil revenue in Alaska or with carbon taxes on fuels in Canada. ${ }^{2}$ Specifying rules for refunding revenues to the polluters, however, can both diminish their incentives to resist the policy and also help the levy be viewed by the public less as a tax and more as a fee. There are legal and institutional differences too: A tax typically implies that the revenues go toward the national budget, whereas a fee is paid to a government agency or municipality for services rendered (e.g., permission to emit or dispose of waste) (Fischer et al. 2020). Traditionally, lump-sum free allocations ("grandfathering") of permits have been used to achieve industry acceptance, starting with the Acid Rain Program in the US. ${ }^{3}$ Newer systems of carbon pricing for industry offer output-based rebates to polluters, including in

\footnotetext{
1 Shultz, George; Becker, Gary (April 7, 2013). "Why We Support a Revenue Neutral Carbon Tax". The Wall Street Journal. Retrieved July 6, 2016.

${ }^{2}$ British Columbia has an explicit carbon tax and a multi-pronged system of rebates to taxpayers. The Canadian Federal Backstop plan rebates revenues from the carbon levy on transportation and heating fuels back to households.

${ }^{3}$ Lump-sum allocations (or rebates) have theoretical appeal since they have in principle no allocation effects as long as they are unrelated to the variables to be regulated. This may have advantages for a policy maker seeking to appease incumbents, but the lack of a clear principle for allocation can be problematic from the viewpoint of transparency and corruption.
} 
California, Canada, and New Zealand. Increasingly, some earmarking of revenues toward emission-reducing activities is being called for. ${ }^{4}$

This paper compares two systems for refunding emission payments to polluters:

- Refund in proportion to output, referred to as output-based refunding (OBR).

- Refund in proportion to abatement expenditure, referred to as expenditure-based refunding (EBR).

Sweden has pioneered the use of OBR for nitrogen oxides $\left(\mathrm{NO}_{x}\right){ }^{5}$ sometimes referred to in the literature as a "refunded emission payment." Among the reasons for the use of OBR rather than a standard tax was the difficulty in setting a sufficiently high price on emissions to motivate abatement when faced with a strong industrial lobby against the tax (Sterner and Isaksson 2006). In Sweden, fees are refunded to the polluters strictly in proportion to output. By contrast, the Norwegian $\mathrm{NO}_{x}$ Fund implements an EBR system that directly ties refunding to actual abatement costs at the firm level. ${ }^{6}$

Output-based refunding (and its quantity-based analogue, output-based allocation) have been quite thoroughly analysed in earlier literature, from the viewpoints of allocation, efficiency, political economy, and effects in special situations of uncertainty, limited competition, etc. See, e.g., Fischer (2011), Gersbach and Requate (2004), Fredriksson and Sterner (2005), Isaksson (2005), and Cato (2010). Note also that OBR corresponds to the outputbased allocation or "benchmarking" in a tradable performance standard (see Fischer 2001). OBR generates an output subsidy and thus gives incentives for excess production. This effect is harmful in a competitive environment, but it can increase welfare under imperfect competition, where output is suboptimal (Gersbach and Requate 2004), unless firms have large differences in market power (Fischer 2011). OBR in unilateral $\mathrm{CO}_{2}$ emissions policies is motivated by its potential to reduce carbon leakage and loss of competitiveness (Edwards and Hutton 2001; Fischer and Fox 2007).

Many carbon pricing schemes ensure some funds are set aside to be used as incentives for households and businesses that invest in weatherizing or in energy-efficient appliances, thus introducing an element of what we call EBR. ${ }^{7}$ In the French taxe parafiscale, the fees (for $\mathrm{NO}_{x}, \mathrm{SO}_{2}, \mathrm{HCl}$, and VOCs) were used to cover administrative costs and to subsidize abatement, as well as research and development, according to quite complicated rules. As an example, "innovative" solutions were subsidized at a rate of $30 \%$ and "ordinary" abatement at only 15\%, with special rules for small firms (see Millock et al. 2004). All in all, it seems the rules were closer to what we call EBR, while maintaining some OBR features, in that the large polluters (who "contributed" a lot to the funds collected) got more of a say in their use and thus seemed to have a larger probability of getting their abatement projects or research projects funded.

\footnotetext{
${ }^{4}$ Regional Greenhouse Gas Initiative (RGGI which covers several US states) earmarks part of the auction revenues for energy efficiency promotion. At a broader political level refunding is also a central part of the discussion in for instance the European Green Deal or the US Green New Deal proposal.

${ }^{5}$ Nitrogen oxides $\left(\mathrm{NO}_{x}\right)$ are waste gases emitted from the combustion of oil, gas, and biofuel that lead to acid rain, eutrophication, and increased concentrations of ground-level ozone. Emissions have ecosystem and health effects, and Norwegian and other countries' emissions are regulated under the Gothenburg Protocol.

${ }^{6}$ For more information about the Norwegian $\mathrm{NO}_{x}$ Fund, see https://www.nho.no/Prosjekter-og-progr ammer/NOx-fondet/The-NOx-fund/.

${ }^{7}$ Refunding is also part of the discussion on carbon taxes in France and Canada, see Criqui et al. (2019).
} 
EBR is an interesting innovation for those situations where it is applicable and has received scant previous attention. There is a related literature on two-part instruments. A number of papers recognize that the Pigouvian tax level may be unattainable for various reasons, and they therefore explore alternatives, such as various combinations of tax and subsidy. See, for instance, Felder and Schleiniger (2002), who analyze the trade-off between efficiency and political feasibility; and Fullerton (1997), who find that, if a tax is infeasible, a satisfactory alternative may combine a subsidy to a clean substitute with a tax on output. (See also Fullerton and Mohr 2003; Bernard et al. 2007; Svendsen et al. 2001; Parry et al. 2012; Johnson 2006, or Walls and Palmer 2001 for similar points.) Renewable portfolio standards, for example, are similar to EBR from a sector perspective, and induce the result of lower emissions prices but higher overall costs; see Fischer and Preonas (2010). None of these articles, however, specifically looks at expenditure-based refunding of an emissions tax. Millock and Nauges (2006) come the closest, analyzing the French taxe parafiscale; however, the refunding there was not automatic, as in the Norwegian case, but rather put into a fund to which firms could apply.

Many developing countries put environmental fees into funds. In these countries, it is common that the large polluters sit on the boards of these funds; although the funds may be used for abatement projects, large polluters have more influence in their use, suggesting that a mix of EBR and OBR principles is actually being used; see Sterner and Coria (2012, pp. 369-373).

The contribution of this paper is the theoretical evaluation of the differences in performance of the EBR and OBR systems for earmarking environmental revenues, and a comparison of their qualities and properties with those of a standard environmental tax. We focus on self-financed funds whose income comes exclusively from fees. An advantage of a Pigouvian tax system without refunding (henceforth referred to as standard tax system, ST) is that it generates public revenues. In this paper, we do not take into consideration the efficiency loss due to the revenue recycling effect (Goulder et al. 1999).

EBR implies a combination of a fee on pollution and a subsidy for abatement technology equipment where the latter is financed by the former. This is not the type of subsidy where the policymaker "buys" each unit of reduction from a baseline at a price $s$ (see, e.g., Kolstad 2000, Chapter 7). Offering subsidies for each unit of abatement clearly implies a perverse output subsidy. Inspired by the Norwegian and French $\mathrm{NO}_{x}$ schemes, we instead model subsidies as the partial payment for the costs of particular pieces of abatement equipment.

By comparing the performance of the systems, we implicitly assume that all systems are applicable to the regulation in question. All systems require measurable emissions. An additional prerequisite for OBR is measurable output, and EBR works well only in situations where you can clearly identify and measure what is a useful expenditure on "abatement technology," rather than general investment in new technology.

We show that, to achieve a certain abatement target, the fee level under OBR must exceed the standard tax rate, whereas with EBR it can be set lower. Compared with a standard tax, both OBR and EBR make technical abatement relatively cheaper than abatement through output reductions. Hence, absent the beforementioned market failures, both EBR and OBR would be welfare inferior to a standard Pigouvian tax, because they lead to lower output reductions. This comparison between an ideal tax and a refunded one does, however, assume that the optimal Pigouvian tax is politically feasible, which is often not the case because of political resistance to high taxes.

Whether EBR or OBR comes closer to the "efficient" reduction in output, in this context, depends on the firms' abatement functions and parameters of the model. In particular, 
we show that if emission is almost linear in output for the industry as whole, OBR gives very small incentives for output reductions. The reason is that the effect of the emission fee on output reduction is almost completely offset by the rebate mechanism, which stimulates output. This makes the output reduction larger under EBR than OBR. We also give examples of functional forms where the opposite result occurs.

We also show that, for a given environmental target, individual firms' preferences for one of the systems or the other depend inter alia on their initial emissions per unit of output and their relative abatement costs. Firms with relatively high emissions-especially if they are expecting soon to carry out maintenance reinvestments that could reduce their emissions significantly-are obviously in favor of a system like EBR that will give them large subsidies and then low fee payments once they have the new technology. Firms with sufficiently low initial emissions per unit of output tend to prefer OBR over EBR. We show that the system with the highest aggregate profits also has the highest social welfare, when social welfare includes only economic costs.

Finally, to consider the case where the government has multiple objectives, we examine a system where emission tax revenues are refunded through some mixture of the OBR and EBR systems. We show that, under reasonable assumptions, such a mixed system makes it possible to achieve both an abatement target and an output target. This is not the case for the pure revenue-neutral OBR and EBR systems; in these systems, output follows endogenously once abatement is determined. Of course, such a mixed system would also combine the administrative complexities of both pure OBR and EBR systems.

In the real world, the regulator's objective function may include more than just pure economic costs, as the regulator may seek to avoid job losses or gain political support by avoiding heavy tax burdens. The EBR and OBR systems can therefore be promising options to achieve greater environmental benefits in situations where such political constraints limit the regulator's use of standard taxes.

\section{A Model for Comparing a Standard Tax with Refunded Fees}

Consider a sector consisting of firms indexed by $i=\{1, \ldots, n\}$, each producing a commodity in quantity $q_{i}$. Production causes emissions, $e_{i}$. Let $e_{i}^{0}$ and $q_{i}^{0}$ denote emissions and production in the absence of environmental policy. Each firm can reduce emissions by installing new, measurable abatement equipment (technology investment) or by reducing production. ${ }^{8}$ For the sake of simplicity, we assume only one type of abatement equipment (y) is relevant for the sector in question. However, firms within the sector may invest in varying levels of the technology. We have

$$
e_{i}=e_{i}^{0}-a_{i}\left(r_{i}, y_{i}\right),
$$

where $a_{i}\left(r_{i}, y_{i}\right)$ is the emission reduction (abatement) function and $r_{i}$ is output reduction:

\footnotetext{
${ }^{8}$ We do not address the dynamic effects or irreversibility of investments (see, e g., Coria, 2009 for such models). Furthermore, in this paper, we do not delve into the incentives for technological progress created by refunding (see Sterner and Turnheim 2006). See also Jaffe et al. (2002), Löschel (2002), and Requate (2005) for surveys on technology investment incentives under various policy instruments. Note also that it may be significant in practice to distinguish between technologies that are easy to measure and control through simple inspection and those that are either too complex or too subtle to allow for simple monitoring.
} 


$$
q_{i}=q_{i}^{0}-r_{i}
$$

For short, we use the following notation for the derivatives: $a_{i r}^{\prime} \equiv \frac{\partial a_{i}\left(r_{i}, y_{i}\right)}{\partial r_{i}}, a_{i r r}^{\prime \prime}(\cdot) \equiv \frac{\partial^{2} a_{i}\left(r_{i}, y_{i}\right)}{\partial r_{i} \partial r_{i}}, a_{i y}^{\prime} \equiv \frac{\partial a_{i}\left(r_{i}, y_{i}\right)}{\partial y_{i}}, a_{i y y}^{\prime \prime}(\cdot) \equiv \frac{\partial^{2} a_{i}\left(r_{i}, y_{i}\right)}{\partial y_{i} \partial y_{i}} \cdot{ }^{9}$ Abatement is increasing in output reductions, and is increasing in abatement equipment at a decreasing rate; $a_{i r}^{\prime}>0, \quad a_{i y}^{\prime}>0, a_{i y y}^{\prime \prime}<0, a_{i r r}^{\prime \prime} \leq 0$. We also assume that the isoquants for the abatement function have the standard curvature, and that both $r_{i}$ and $y_{i}$ are normal input factors in the production of $a_{i}$. Details are given in "Appendix 1", where we also give an interpretation of the abatement function.

As a starting point, we consider internal solutions for firms' production decisions. Impacts on exit and entry decisions are discussed in Sect. 5. Let $E$ stand for the sector's total emissions, assumed to be uniformly dispersed; that is:

$$
E=\sum_{i} e_{i}
$$

We define total output and total abatement as

$$
Q=\sum_{i} q_{i}
$$

and

$$
A=\sum_{i} a_{i} \equiv \sum_{i} e_{i}^{0}-E \equiv E^{0}-E .
$$

Furthermore, we define total amount of abatement equipment

$$
Y=\sum_{i} y_{i}
$$

We assume that all market shares are so small that all firms take all prices, taxes/fees, and subsidies as given.

\subsection{Standard Tax}

The standard tax system is a tax-alone system, that is, with no refunding of the tax revenue, and the tax level is set equal to the Pigouvian level.

With a standard tax, an individual firm has the following payoff:

$$
\pi_{i}=p q_{i}-c_{i}\left(q_{i}\right)-m y_{i}-t \cdot\left(e_{i}^{0}-a_{i}\left(r_{i}, y_{i}\right)\right),
$$

where $p$ is the product price, ${ }^{10} c_{i}\left(q_{i}\right)$ are production costs of $q_{i}, t$ is the tax rate on emissions, and $m$ is the (annuity) price per unit of abatement equipment $y_{i}$. We apply the standard

\footnotetext{
9 This notation for the derivatives of functions with more than one argument is used throughout the paper. For functions with only one argument, we omit the argument in the subscript.

${ }^{10}$ Without loss of generality, we assume the same product price for all producers. This may be interpreted as either a situation with homogeneous goods or a situation with heterogeneous goods and a choice of units for each good, which makes all prices identical. In the latter case, $p Q$ must be interpreted as the total value of production.
} 
assumptions that marginal cost of production is positive and increasing: $c_{i}^{\prime}>0, c_{i}^{\prime \prime}>0 .{ }^{11}$ Maximizing the profit functions yields the following first-order conditions:

$$
\begin{aligned}
& \frac{m}{a_{i y}^{\prime}\left(r_{i}, y_{i}\right)}=t, \\
& \frac{p-c_{i}^{\prime}}{a_{i r}^{\prime}\left(r_{i}, y_{i}\right)}=t .
\end{aligned}
$$

The second order conditions are

$$
\begin{aligned}
& -c^{\prime \prime}+t a_{r r}^{\prime \prime}<0 \\
& t a_{y y}^{\prime \prime}<0 \\
& -c^{\prime \prime} a_{y y}^{\prime \prime}+t\left[a_{r r}^{\prime \prime} a_{y y}^{\prime \prime}-\left(a_{r y}^{\prime \prime}\right)^{2}\right]>0
\end{aligned}
$$

The left-hand side of (8) expresses the marginal cost of reducing emissions through abatement equipment, and the left-hand side of (9) expresses the marginal cost of emission reductions through output reductions. The intuition behind the first-order conditions is well known: the marginal cost of emission reductions should equal the marginal benefit of emission reductions $(t)$, whether the emission reductions occur through abatement technology (8) or through output reduction (9).

It is well known that (8) and (9) lead to a cost-effective (cost-minimizing) combination of output reduction and abatement technology deployment for all emission levels, and also lead to an optimal emission level, as long as the level of $t$ corresponds to the true social marginal damage, the Pigouvian tax level, and no other market failures are present. In the following, we refer to the expressions on the left-hand side of (8) and (9) as the social marginal cost of reducing emissions through abatement equipment, and the social marginal cost of emission reductions through output reductions, respectively. As we will see below, the refunding systems make the firms' private marginal cost of abatement differ from the social marginal cost of abatement.

\subsection{Mechanism Design for Output-Based Refunding Emissions Payments}

With a standard tax, the total tax revenue, $t E$, is collected by the government as public revenue. A fund system implies that the tax becomes a fee and the revenue is collected by the fund. We shall focus on such cases where all the revenue is reimbursed fully to the polluters.

In an output-based refunding scheme, fees are refunded in proportion to output $q_{i}$. Let $b$ denote the refund per unit production and $t$ is the fee (corresponding to a standard tax). In equilibrium, to satisfy the budget constraint $(Q b=t E)$, the policy makers must set

$$
b=t \bar{e}_{q},
$$

\footnotetext{
11 In real life, abatement technologies may also affect the cost of producing $q$. However, our simplification does not affect the main results of the paper.
} 
where $\bar{e}_{q} \equiv E / Q$, and $E$ and $Q$ are given by (3) and (4), respectively. This corresponds exactly to refunding the total fee revenue $t E$ in proportion to the firms' market shares, $q_{i} / Q$, as in the Swedish $\mathrm{NO}_{x}$ scheme. ${ }^{12}$

Because all firms' market shares are assumed to be small, they take $b$ as given, ${ }^{13}$ although the equilibrium value $b$ is endogenous. The payoff to firm $i$ is

$$
\pi_{i}=p q_{i}-c_{i}\left(q_{i}\right)-m y_{i}-t \cdot\left(e_{i}^{0}-a_{i}\left(r_{i}, y_{i}\right)\right)+q_{i} b .
$$

The firms maximize their payoffs specified in (1), (2) and (12): the first-order conditions, after inserting for $b$ from (11), are as follows ${ }^{14}$ :

$$
\begin{gathered}
\frac{m}{a_{i y}^{\prime}\left(r_{i}, y_{i}\right)}=t, \\
\frac{p-c_{i}^{\prime}}{a_{i r}^{\prime}\left(r_{i}, y_{i}\right)}=t \cdot\left(1-\frac{\bar{e}_{q}}{a_{i r}^{\prime}\left(r_{i}, y_{i}\right)}\right) .
\end{gathered}
$$

As in the standard tax system, we find that the social marginal cost of emissions reductions through abatement technology is equated with the level of the fee for all firms; see Eq. (13). However, we see from (14) that the social marginal cost of avoided emissions through output reductions is no longer equal to the level of the fee $t$ but is multiplied by the factor $\left[1-\bar{e}_{q} / a_{i r}^{\prime}\left(r_{i}, y_{i}\right)\right]<1$.

The OBR system implies an extra cost to the firm of abatement through output reductions, compared with the standard tax system: reduced production leads to lower refunding. The firm's marginal loss of refunding that follows from abatement through reduced output equals $t \cdot \bar{e}_{q} / a_{i r}^{\prime}\left(r_{i}, y_{i}\right)$. Hence, the firm's marginal cost of reduced output exceeds the social cost of reduced output. Output is stimulated in two different directions. The emission fee makes production more costly, whereas the refunding mechanism makes production less costly.

\subsection{Expenditure-Based Refunding (EBR)}

With an expenditure-based refunding scheme, all fee revenues are refunded to the polluters in proportion to their expenditures for abatement equipment. Let $s$ denote the subsidy per unit abatement equipment. In equilibrium, to satisfy the budget constraint $(s Y=t E)$, the policy makers must set

$$
s=t \bar{e}_{y},
$$

where $\bar{e}_{y} \equiv E / Y$, and $E$ and $Y$ are given by (3) and (6), respectively.

\footnotetext{
12 Gersbach and Requate (2004) use this setup in the competitive version of their model. Meunier et al. (2018) explore situations without budget balance and under uncertainty.

13 See Fischer (2011) and Sterner and Isaksson (2006) for a model of an OBR system where strategic manipulation of the total emission revenues is discussed.

14 Second-order conditions equal the second-order conditions for the standard tax system (see "Appendix $2 ")$. However, if we do not assume that the output share of each firm is treated as given, there is an extra factor $\left(1-q_{i} / Q\right)$ in (13) and (14). When all firms' share of total output is small, this factor is negligible (see further Fischer 2011 and Sterner and Isaksson, 2006).
} 
Because all firms' market shares are assumed to be small, they take $s$ as given, although the equilibrium value of $s$ is endogenous. The payoff to firm $i$ is

$$
\pi_{i}=p q_{i}-c_{i}\left(q_{i}\right)-(m-s) \cdot y_{i}-t \cdot\left[e_{i}^{0}-a_{i}\left(r_{i}, y_{i}\right)\right] .
$$

The share of the equipment expenditure $\left(m y_{i}\right)$ refunded to the firms through the subsidy scheme, equals $s / m$. It must be true that $s<m$. To see this, assume the opposite. With a positive emission tax, it would then be optimal for all firms to choose an "infinitely" high $y_{i}$, or at least so high that emissions become zero. This gives $E / Y=\bar{e}_{y}=0$, which, from (15), contradicts $s \geq m$.

Assuming the firm under EBR maximize the payoffs specified in (1) and (16), then the first-order conditions, after inserting for $s$ from (15), are given by ${ }^{15}$

$$
\begin{gathered}
\frac{m}{a_{i y}^{\prime}\left(r_{i}, y_{i}\right)}=t \cdot\left[1+\frac{\bar{e}_{y}}{a_{i y}^{\prime}\left(r_{i}, y_{i}\right)}\right], \\
\frac{p-c_{i}^{\prime}}{a_{i r}^{\prime}\left(r_{i}, y_{i}\right)}=t .
\end{gathered}
$$

By comparing (8) and (17), we see that the social marginal cost of emissions avoided through $y$ is no longer equal to the level of the fee $t$ but is multiplied by the factor $\left[1+\bar{e}_{y} / a_{i y}^{\prime}\left(r_{i}, y_{i}\right)\right]>1$.

The EBR system implies a lower cost to the firm of abatement through $y$, compared with the standard tax system. The firm's marginal increase in refunding following from abatement through $y$ equals $t \bar{e}_{y} / a_{i y}^{\prime}\left(r_{i}, y_{i}\right)$. Hence, the firm's marginal cost of abatement through $y$, inclusive of the subsidy, is lower than the marginal social cost. The expenditure-based refunding implies double incentives for investment in abatement equipment: not only are emissions taxed but abatement equipment is subsidized.

\section{A Comparison of Two Mechanisms for Refunding}

In this section, we evaluate the EBR and OBR systems regarding cost-effectiveness, and we compare the fee levels and distribution of costs across firms. The standard tax system is used as a benchmark. However, we acknowledge that a standard tax system may, for political or practical reasons, not be achievable or preferred, as noted earlier and discussed further in Sect. 7. We introduce the subscripts ST, OB and EB to refer to the outcomes of the standard tax system, the OBR system, and the EBR system, respectively.

\subsection{Comparisons with the Same Fee Level}

As we saw from the previous section, the output effect of a fee under the OBR system is weaker compared with a tax under a standard tax system. Under the EBR system,

\footnotetext{
15 Because $s<m$, the second-order conditions equal the second-order conditions for the standard tax system.
} 
on the other hand, the fee on pollution is complemented with a subsidy on abatement equipment, making abatement less costly. Comparing the two systems with the outcome of a tax system, we must decide whether the comparison assumes equal tax rates or equal abatement. We start with the former. OBR combines an emission tax with a subsidy to output. This subsidy increases the firm's income per unit output, and thus makes it more costly to reduce output compared to a tax alone system, while not directly altering the incentives for investments in abatement technology. EBR combines an emission tax with a subsidy to abatement equipment, encouraging more abatement equipment than a tax alone system, while not directly altering the incentives for output reductions. We find that EBR gives more and OBR gives less abatement than a standard Pigouvian tax of the same magnitude.

Proposition 1 For all $t, a_{i}^{E B}(t)>a_{i}^{S T}(t)>a_{i}^{O B}(t)$

Proof With equal tax rates $(t)$, we see from Eqs. (7) and (12) that the payoff function under OBR equals the payoff function under the ST system if $p$ in (7) is replaced by $p+b$. The payoff function under EBR [eq. (16)], equals the payoff function under the ST system if $m$ in (7) is replaced by $m-s<m$. In "Appendix 2" we show that the abatement under the ST system is decreasing in $p$ and $m$. $\left(\partial a_{i}^{S T} / \partial m<0\right.$ and $\left.\partial a_{i}^{S T} / \partial p<0\right)$.

Proposition 2 Compared to a situation without any environmental policy, the EBR system leads to lower production for all firms, whereas the OBR system may lead to higher production for some or all firms.

Proof By rearranging the first order conditions (9) and (13), we find that the EBR system gives

$$
p-c_{i}^{\prime}\left(q_{i}^{0}-r_{i}^{E B}\right)=a_{i r}^{\prime}\left(r_{i}^{E B}, y_{i}^{E B}\right) \cdot t,
$$

whereas the OBR system gives

$$
p-c_{i}^{\prime}\left(q_{i}^{0}-r_{i}^{O B}\right)=t \cdot\left[a_{i r}^{\prime}\left(r_{i}^{O B}, y_{i}^{O B}\right)-\bar{e}_{q}^{O B}\right] .
$$

If $t>0$, EBR will lead to less output than with no policy $(t=0)$, whereas OBR leads to higher output in equilibrium if $a_{i r}^{\prime}\left(r_{i}^{O B}, y_{i}^{O B}\right)<\bar{e}_{q}^{O B}$, that is, if marginal emissions are below the average.

For the EBR system, the emission tax implies higher cost of production (as long as the firm's emissions after abatement remain positive). Thus, the EBR system will induce all firms to reduce production. For the OBR system, the refunding mechanism stimulates production. Thus, for firms with relatively low marginal emissions $\left(a_{i r}^{\prime}\right)$, the refunding per unit production may exceed the tax per unit production. In that case, it is optimal to expand production under the OBR system, beyond the optimal level without any tax on emissions. This may occur for all firms if emissions have a high fixed component and are relatively insensitive to output; for example, maintaining heat in a blast furnace is energy intensive regardless of the amount of metal being smelted. 


\subsection{Comparisons with the Same Target Level of Abatement}

Building on this result, we switch to a comparison between different levels of fees, designed to give the same level of abatement. Proposition 3 shows us that the tax/subsidy (EBR) requires a fee that is lower than the standard tax, whereas output-based refunding $(\mathrm{OBR})$ requires a higher fee. ${ }^{16}$

Proposition 3 Consider a given target for abatement, and let $\bar{t}^{S T}, \bar{t}^{O B}$, and $\bar{t}^{E B}$ denote the tax/fee levels that ensure that the target is met in the standard tax system, the OBR system, and the EBR system, respectively. We have $\bar{t}^{E B}<\bar{t}^{S T}<\bar{t}^{O B}$.

Proof The abatement in the standard tax system is an increasing function of the tax rate for all firms $\left(\partial a_{i} / \partial t>0\right.$, see "Appendix 2"). Furthermore, we know from Proposition 1 that $a_{i}^{E B}(t)>a_{i}^{S T}(t)>a_{i}^{O B}(t)$, for all t. Hence, for $\sum_{i} a_{i}^{S T}\left(\bar{t}^{S T}\right)=\sum_{i} a_{i}^{O B}\left(\bar{t}^{O B}\right)=\sum_{i} a_{i}^{E B}\left(\bar{t}^{E B}\right)$, we must have $\bar{t}^{E B}<\bar{t}^{S T}<\bar{t}^{O B}$.

The tax rate in the EBR system can be set lower for identical emissions reductions, since the tax effect is combined with a subsidy on abatement equipment. The tax rate in the OBR system must be set higher because the tax effect is combined with a subsidy to production. Although the OBR does have a higher fee level, the average company pays nothing, thanks to the automatic refund, and both theory and experience show that, under these circumstances, even high fee levels may be more acceptable than a tax (see Fredriksson and Sterner 2005).

Although the regulator can achieve the same total abatement level in all three systems by appropriate tax or fee levels, the distribution of abatement across firms can differ. The standard tax system minimizes the cost of achieving a specific abatement target. Hence, if the EBR or the OBR system leads to another distribution across firms, the total cost of the abatement target increases. Furthermore, even if the distribution of abatement across firms are identical in all systems, both the EBR and OBR systems will lead to a combination of abatement equipment and output reduction that is cost-ineffective compared with the ideal first best (if and when that is achievable or applicable). In that first best, a standard tax leads to a cost-minimizing combination of output reductions and abatement equipment for all firms. Proposition 4 formalizes this.

Proposition 4 Consider a firm for which all three systems leads to the same abatement level. That abatement level will be achieved by too much investment in abatement equipment and too little output reduction under both OBR and EBR, compared with a standard tax system.

Proof In the first-order conditions for output, (9), (14) and (18), we replace the equilibrium value of $t$ that must hold from the first-order conditions for abatement equipment, (8), (13) and (17). This gives

\footnotetext{
${ }^{16}$ The latter result is well documented in the litterature; see e.g., Fischer (2001) and Fischer and Fox (2007).
} 


$$
\begin{gathered}
\frac{p-c_{i}^{\prime}\left(q_{i}^{S T}\right)}{m}=\frac{a_{i r^{S T}}^{\prime}}{a_{i y^{S T}}^{\prime}} \\
\frac{p-c_{i}^{\prime}\left(q_{i}^{O B}\right)}{m}=\frac{a_{i r^{O B}}^{\prime}-\bar{e}_{q^{O B}}}{a_{i y^{O B}}^{\prime}}, \\
\frac{p-c_{i}^{\prime}\left(q_{i}^{E B}\right)}{m}=\frac{a_{i r^{E B}}^{\prime}}{a_{i y^{E B}}^{\prime}+\bar{e}_{y^{E B}}} .
\end{gathered}
$$

Since $\bar{e}_{q}>0$, inserting $\left(q_{i}^{O B}, y_{i}^{O B}\right)$ from (22) into (21) would give us $<$ instead of $=$ in (21). To restore equality, $q_{i}$ must decline, since $c_{i}^{\prime \prime}\left(q_{i}\right)>0$ and $a_{i r}^{\prime} / a_{i y}^{\prime}$ is lower the smaller is $q_{i}$ (i.e. the higher is $r_{i}$ ) due to the curvature of the isoquants. Hence, we must have that $q_{i}^{O B}>q_{i}^{S T}$ (and $y_{i}^{O B}>y_{i}^{S T}$ ). Since $\bar{e}_{y}>0$, the same reasoning applied to (23) gives the result that $q_{i}^{E B}>q_{i}^{S T}$ (and $y_{i}^{E B}>y_{i}^{S T}$ ).

We know from Proposition 3 that the tax rates, and thus the marginal cost of emissions, will differ across system. However, we know from the first order conditions [(8)-(9), (13)-(14) and (17)-(18)], that within each system, the marginal cost of reducing output equals the marginal benefit of output reduction, and the marginal cost of abatement equipment equals the marginal benefit of abatement equipment. Thus, for each system, and tax rates, the relative marginal cost of $r$ and $y$, must equal the relative marginal benefit of $r$ and $y$, in optimum. The left-hand sides (21), (22) and (23) express the marginal cost of output reductions (in terms of forgone revenue) relative to the marginal cost of abatement technology (in terms of the price per unit abatement equipment). The right-hand sides of (21), (22) and (23) express marginal benefit of output reductions relative to the marginal benefit of abatement equipment [including the subsidy (EBR) and the rebate (OBR)]. Although the design of the OBR and EBR differ substantially, they both make it relatively more beneficial for the firm to achieve an abatement level through abatement equipment than through output reduction, compared with a standard tax. This follows from the fact that the EBR subsidizes abatement equipment, whereas the OBR subsidizes output.

Proposition 5 Comparing the OBR and EBR systems with the same total abatement level, which of the two systems has the lower equilibrium output depends on the abatement functions and parameters of the model.

Proof If Proposition 5 is true for identical firms and emission function with constant elasticities, it must also be true for the more general case of different firms and emission functions. If all $n$ firms are identical, $q^{E B}<q^{O B}$ (i.e., $r^{E B}>r^{O B}$ ) follows from the right-hand side of (22) being larger than the right-hand side of (23):

$$
q^{E B}<q^{O B} \Leftrightarrow \frac{a_{r^{E B}}^{\prime}}{a_{y^{E B}}^{\prime}+\bar{e}_{y^{E B}}}>\frac{a_{r^{O B}}^{\prime}-\bar{e}_{q^{O B}}}{a_{y^{O B}}^{\prime}} .
$$

Note from (1) and (2) that $e=e^{0}-a\left(q^{0}-q, y\right)=e(q, y)$ and $a_{r}^{\prime}=e_{q}^{\prime}$ and $a_{y}^{\prime}=-e_{y}^{\prime}$.The condition above can be written as: 


$$
q^{E B}<q^{O B} \Leftrightarrow \frac{y^{E B}}{q^{E B}} \cdot\left[\frac{\varepsilon_{q}}{1-\varepsilon_{y}}\right]>\frac{y^{O B}}{q^{O B}} \cdot\left[\frac{\varepsilon_{q}-1}{-\varepsilon_{y}}\right],
$$

where $\varepsilon_{q} \equiv e_{q}^{\prime} / \bar{e}_{q}>0$ and $\varepsilon_{y} \equiv e_{y}^{\prime} / \bar{e}_{y}<0$ is the elasticity of output and abatement technology of the emission function $e(q, y)$, respectively. We find that $\left[\varepsilon_{q} /\left(1-\varepsilon_{y}\right)\right]>(<)\left[\left(\varepsilon_{q}-1\right) /-\varepsilon_{y}\right]$ for $\varepsilon_{q}+\varepsilon_{y}<(>) 1$, where $\varepsilon=\varepsilon_{q}+\varepsilon_{y}$ is the scale elasticity of the emission function $e(q, y)$. Note that, for a given emission target, $y / q$ is increasing (decreasing) in $q$ for $\varepsilon<(>) 1$, and constant for $\varepsilon=1$. Thus, we see from (19) and (20), and $c^{\prime \prime}>0: q^{E B}<(>) q^{O B}$ for $\varepsilon<(>) 1$, and $q^{E B}=q^{O B}$ for $\varepsilon=1$.

Since both OBR and EBR make abatement through technology investments relatively less costly than abatement through output reduction, we cannot in general tell which of the systems that leads to the lowest output. In the proof of Proposition 5 we used an emission function with constant elasticities, and identical firms, to show that it could go in both directions, depending on the scale elasticity being below or above 1 .

It seems reasonable that the scale elasticity is below 1, i.e. that a proportional increase in $q$ and $y$ will increase $e$ less than proportionally, but the opposite may also occur. In most cases increasing output for a given $y$ will increase emissions about proportionally, so that if $y$ also is increased, emissions will increase less than proportionally with $q$. Thus $\varepsilon<1$, and $q^{E B}<q^{O B}$. This will be the case if emission is almost linear in output ( $\varepsilon_{q}$ is close to 1 ), since $\varepsilon_{y}$ is negative. ${ }^{17}$ As pointed out in Sect. 2.2, OBR stimulates output in two different directions. For $\varepsilon_{q}$ close to 1 , the effect of the emission tax is almost completely offset by the rebate mechanism. This gives very small incentives for output reductions under OBR.

For $\varepsilon_{q}>1$, OBR gives incentives for output reductions, and this occur for example if emissions are proportional to an input, and output has decreasing returns to this input. We find that $q^{E B}>q^{O B}$ for $\varepsilon_{q}>1$ if the absolute value of $\varepsilon_{y}$ is sufficiently small to ensure that $\varepsilon>1$. A smaller $\left|\varepsilon_{y}\right|$ means that abatement equipment has a smaller impact on emission reductions. It thus makes it relatively more costly to reduce emissions through abatement equipment than output reductions under both OBR and EBR. However, the relative marginal benefit of $r$ and $y$ is affected less under EBR, because less $y$ increases $\bar{e}_{y}$, and thereby the subsidy per unit abatement equipment. Hence, the smaller $\left|\varepsilon_{y}\right|$, the larger $q^{E B} / q^{O B}$.

It is also clearly of interest which system gives higher social welfare and which system might be preferred by the industry. Proposition 6 gives a partial answer to the first question, whereas Proposition 7 and 8 deal with the individual firms' preferences for OBR versus EBR.

Proposition 6 Comparing the OBR and EBR systems with the same total abatement level,

(a) the system that has highest social welfare also has highest aggregate profits

(b) the system with lowest equilibrium output has the highest social welfare and aggregate profits.

\footnotetext{
17 The conclusion that EBR gives smaller output than OBR when emissions are almost linear in output will hold also for general functions, as we see that the right-hand side of (19) is close to zero when $a_{r}^{\prime}=\bar{e}_{q}$, while the right hand side of (20) remains strictly positive.
} 
Proof The proof of (a) follows from the following three properties of our model: (i) consumer surplus is equal across systems because output prices are given, (ii) government revenue is the same under OBR and EBR because all emission taxes are refunded to the industry, (iii) emissions are by assumption the same under the two systems.

We know that both the EBR and OBR mechanisms lead to higher output and higher investments in abatement equipment than the standard tax system (Proposition 4). The more the outcome deviates from the first best, the higher the total cost of achieving the emissions target will be, hence $b$ ) is proven.

In Proposition 6, we have implicitly defined social welfare in the "standard" way (as the sum of consumer, producer and government surplus). However, as we discussed in the introduction, the motivation for refunding is often to prevent firm closure, job loss, and carbon leakage. The establishment of a fund is typically motivated by a preference for a different combination of output reductions and abatement technology than what follows from a standard tax system. These motivations indicate that policy preferences give some weight to output in addition to traditionally defined social welfare. Thus, it is not obvious which of the two systems would be politically preferred, even if we knew which system gave the lowest output (and hence the highest social welfare as narrowly defined, cf. Prop 5).

If all firms were identical, they all would prefer the system (OBR or EBR) that gave the lowest output, since this system also would give the highest profits to each firm. In general, however, firms differ, so their preferences over the two systems may differ. As we shall see from the two subsequent propositions, a relatively robust conclusion is that firms with sufficiently low initial emissions per unit of output will prefer OBR over EBR.

Proposition 7 Under EBR, all firms are worse off than they would be without any environmental policy, while under OBR, firms with sufficiently low initial emissions per unit of output (compared to the average) will be better off than without any environmental policy.

Proof All firms are worse off with EBR policy than with no policy, because only a share of the investment costs is reimbursed $(s<m)$, and they pay a positive emission tax. From Eq. (12) it follows that firms with lower initial emissions per unit output than the equilibrium average emissions per unit output $\left(e_{i}^{0} / q_{i}^{0}<E / Q\right)$ will receive a net subsidy without undertaking any abatement. To the extent they do abate, this will further increase profits.

Note that there will not necessarily exist firms that have $\left(e_{i}^{0} / q_{i}^{0}<E / Q\right)$. If e.g. all firms are equal no firms can have this property. In this case all firms are worse off under OBR than no policy, since firms pay no net tax under OBR, but bear the cost of reducing their emissions.

To further illustrate the difference between OBR and EBR, assume that the only difference between firms is their initial emission level and hence initial emissions per unit of output (since initial output is identical across firms when cost functions are identical). We then can state the following:

Proposition 8 Assume that the only difference between firms is the value of their initial emissions $e_{i}^{0}$, and that firms' preferences over the two systems depend only on their equilibrium profits. Then preferences for OBR versus EBR as a system to meet an equivalent environmental target are one of the following: 
- all firms prefer $O B R$ to $E B R$

- all firms prefer EBR to $O B R$

- there exists a threshold ẽ such that firms with $e_{i}^{0}<\tilde{e}$ prefer OBR and firms with $e_{i}^{0}>\tilde{e}$ prefer $E B R$.

Proof The first two possibilities follow trivially from Propositions 5 and $6 \mathrm{~b}$. Profits are continuous in initial emissions. Because only initial emissions differ across firms, there must exist some initial emission level $\tilde{e}$ that makes profits equal under OBR and EBR if some firms prefer OBR and some prefer EBR. Consider a firm with an emission level higher than $\tilde{e}$. From (8) and (11), we know that $\partial \pi_{i} / \partial e_{i}^{0}=-t$ for both systems, so a firm with an emission level higher than $\tilde{e}$ will have lower profits than a firm with an emission level equal to $\tilde{e}$. From Proposition 2, we know that to meet the same emissions target, the tax rate $t$ must be higher under OBR than under EBR, so the difference in profits is larger under OBR than under EBR. Hence, firms with $e_{i}^{0}>\tilde{e}$ have lower profits under OBR than under EBR. By the same reasoning, firms with $e_{i}^{0}<\tilde{e}$ have higher profits under OBR than under EBR. ${ }^{18} \square$

For the special case of identical firms, all firms will have the same preferences over the two refunding systems. They will in this case all prefer the system that gives the lowest output, which is also the system that gives highest social welfare. Which of the two systems gives lowest output is not obvious, but for the special case of constant elasticities it seems reasonable to expect that the EBR system gives the lowest output and hence is the system preferred by the firms (since a scale elasticity below one seems most reasonable for the emission function).

With heterogeneous firms, firms may differ with respect to which of the two refunding systems they prefer. In particular, Proposition 8 suggests that "green" firms (low BaU emissions) tend to prefer OBR, while "brown" firms (high BaU emissions) prefer EBR. The intuition behind this result is related to Proposition 3: To obtain the same amount of abatement, the emission tax must be higher under OBR than under EBR. Since "brown" firms are affected most by a high tax rate, these firms will tend to prefer EBR, which has the lower tax rate. This intuition suggests that the result in Proposition 8 is much more general than for the special case assumed there: The fact that the emission tax is higher under OBR than EBR implies that firms with high emissions per unit of output will be most negatively affected by the OBR system.

\section{A Mixed Refunding System ${ }^{19}$}

As mentioned previously, the government may have preferences with regard to the output level of the sector. If the government has a quantitative target not only for aggregate emissions, but also for aggregate output, it will not generally be possible to achieve both targets with either of the two refunding systems considered previously. Given the revenue constraint (zero net revenue to the government), the two systems will generally give different output levels for any

\footnotetext{
${ }_{18}$ Notice that it follows directly from the proof that if the comparison was for a given tax rate (instead of a given abatement level) all firms would for the case considered in Proposition 8 have identical preferences, i.e. all would prefer EBR or all would prefer OBR.

19 This section draws heavily on insight provided by Phillippe Bontems (2017).
} 
given common abatement level. Which of the two systems is best (i.e., output closest to the target) will hence depend on what the output target is.

Revenue need not be reimbursed only according to output or only according to abatement expenditures. More generally, revenue reimbursement could be linked to both these variables. In this section we therefore analyse a hybrid system whereby the emission tax is reimbursed partly based on output and partly based on abatement expenditures. We study the properties of such a hybrid system below, both with and without revenue neutrality. We restrict the analysis to the case of identical firms; the subscript $i$ is therefore omitted in this section.

Assume there is an emission tax $t$, an output subsidy $b$, and a subsidy $s$ for abatement expenditures. The profit of each firm is hence given by

$$
\pi=(p+b) q-c(q)-(m-s) y-t\left(e^{0}-a(r, y)\right) .
$$

The first-order conditions are

$$
\begin{gathered}
p+b-c^{\prime}(q)-t a_{r}^{\prime}=0, \\
t a_{y}^{\prime}-(m-s)=0,
\end{gathered}
$$

The second-order conditions are as before given by (10), and imply that we must have $t>0$. Equations (25) and (26) may be rewritten as

$$
\begin{gathered}
b=t a_{r}^{\prime}-\left(p-c^{\prime}(q)\right), \\
s=m-t a_{y}^{\prime} .
\end{gathered}
$$

For a given target for output and abatement, the right-hand sides of (27) and (28) depend only on the emission tax $t$. For any given $t$, these equations tell us what $b$ and $s$ must be to achieve the targets for emissions and output (and, as a residual, abatement equipment). To achieve the desired emissions and output, one could, e.g., have $s=0, t=m / a_{y}^{\prime}$, and $b$ determined by (27) with this value of $t$ inserted. Alternatively, we could have $b=0$, $t=\left(p-c^{\prime}(q)\right) / a_{r}^{\prime}$, and $s$ determined by (28) with this value of $t$ inserted.

Different combinations of $(t, b, s)$ that give the same level of abatement and output will generally give different values for the revenue to the government. This revenue is given by

$$
V=t e-b q-s y
$$

Inserting from (27) and (28) gives

$$
V=t e-\left[t a_{r}^{\prime}-\left(p-c^{\prime}\right)\right] q-\left[m-t a_{y}^{\prime}\right] y
$$

Using $e_{q}^{\prime}=a_{r}^{\prime}>0$ and $e_{y}^{\prime}=-a_{y}^{\prime}<0$ we can rewrite this as

$$
V=t\left(e-q e_{q}^{\prime}-y e_{y}^{\prime}\right)+\left(p-c^{\prime}\right) q-m y
$$

or

$$
V=t e(1-\varepsilon)+\left(p-c^{\prime}\right) q-m y
$$


where as before $\varepsilon=\varepsilon_{q}+\varepsilon_{y} \equiv e_{q}^{\prime} / \bar{e}_{q}+e_{q}^{\prime} / \bar{e}_{q}$ is the scale elasticity of the emission function $e(q, y)$.

For given levels of output and abatement, that is, $d q=0$ and $d y=0$, it follows from (27), (28) and (30) that

$$
\begin{gathered}
\frac{d b}{d t}=a_{r}^{\prime}>0 \\
\frac{d s}{d t}=-a_{y}^{\prime}<0 \\
\frac{d V}{d t}=e(1-\varepsilon)
\end{gathered}
$$

We immediately see that $V$ is increasing or declining in $t$ depending on whether the scale elasticity is smaller than or larger than 1.

In Sect. 3 we argued that it seems reasonable that this scale elasticity is below 1, i.e. that a proportional increase in $q$ and $y$ will increase $e$ less than proportionally. Recall also from Sect. 3 that for the case of constant elasticities of the function $e(q, y), \varepsilon<1$ implies that $q^{E B}<q^{O B}$. We shall nevertheless consider both the case of $\varepsilon<1$ and $\varepsilon>1$ below.

From (31) (and the reasoning leading to this equation) we have the following Proposition:

Proposition 9 If firms are identical, output and abatement may be held unchanged by increasing $t$ and $b$ and reducing $s$. Such a change in the policy parameters $(t, b, s)$ will increase (reduce) the government's revenue and hence reduce (increase) profits provided the scale elasticity of the emission function $e(q, y)$ is lower (higher) than one.

This proposition immediately leads to our next result:

Proposition 10 For any given policy target for output and abatement, identical firms prefer the EBR system to all mixed systems with $b>0$, provided the scale elasticity of the emission function $e(q, y)$ is lower than one. If this scale elasticity is larger than one, identical firms prefer the OBR system to all mixed systems with $s>0$.

This last Proposition has some similarities to the results given in the proof of Proposition 5: In both cases EBR is the most preferred case if the scale elasticity is smaller than one. For the case treated in Proposition 5, the reason for this was that output was lower under EBR than under OBR. In the case of Proposition 10, output was the same across systems, but profits are higher under EBR than all other mixed systems due to the government revenue being lower.

Without the revenue constraint, it is possible to obtain any emission and output target with an appropriate combination of an emission tax and a subsidy to either output or abatement equipment. Different combinations give different profits, as explained above. The OBR and EBR systems considered previously assumed revenue neutrality. It is therefore of interest also to consider the hybrid system when revenue neutrality is imposed. In particular, it is of interest to know whether it is possible to achieve the $\mathrm{BaU}$ output level $q^{0}$, since an important reason for not using the standard tax will typically be to avoid output being reduced.

With revenue neutrality, i.e. $V=0$, it follows from (30) that 


$$
t e(1-\varepsilon)=m y-\left(p-c^{\prime}\right) q
$$

The second order conditions for an interior solution imply that $t>0$. This leads to the following proposition:

Proposition 11 If the scale elasticity of the emission function $e(q, y)$ is lower than one, a revenue neutral hybrid system can be designed so that the BaU output level $q^{0}$ together with any abatement level can be achieved.

Proof From (32) it follows that any abatement level $a$ and the BAU output level $q^{0}$ may be achieved with an emission $\operatorname{tax} t=m y\left(a, q^{0}\right) / e(1-\varepsilon)>0$.

With this tax, it follows from (27) and (28) that $b=m y\left(a, q^{0}\right) a_{r}^{\prime} / e(1-\varepsilon)>0$ and $s=m\left(1-y\left(a, q^{0}\right) a_{y}^{\prime} / e(1-\varepsilon)\right)$. Notice that it is not obvious that $s$ is positive: The condition for $s>0$ is $e(1-\varepsilon)>y a_{y}^{\prime}$, which is equivalent to $e-q e_{q}^{\prime}-y e_{y}^{\prime}>-y e_{y}^{\prime}$, i.e. $\varepsilon_{q}=e_{q}^{\prime} / \bar{e}_{q}<1$. It is not obvious that this condition holds. On the contrary, the opposite condition will hold if emissions are proportional to an input and output has decreasing returns to this input.

If the scale elasticity $\varepsilon$ is larger than one, the left-hand side of (32) is negative for $t>0$. The right-hand side of (32) must therefore also be negative, giving the following Proposition:

Proposition 12 If the scale elasticity of the emission function $e(q, y)$ is higher than one, all output levels that can be achieved through a revenue neutral hybrid system are below the BAU output level.

Proof The right-hand side of (32) is negative in this case, implying $p>c^{\prime}(q)$, which implies $q<q^{0}$.

In Sect. 3 we showed that $q^{E B}>q^{O B}$ if $\varepsilon>1$ (for constant elasticities). From Proposition 12 it is clear that both these output levels are below the $\mathrm{BaU}$ level if $\varepsilon>1$.

It follows from the two last propositions that the properties of a revenue neutral hybrid system depend on the the size of the scale elasticity $\varepsilon$ of the emission function. We have previously argued that $\varepsilon<1$ is the most plausible case. For this case it is possible to achieve any desired emission level without affecting the BAU output level. If revenue neutrality is not imposed, it follows from our analysis that any combination of emission and output levels can be achieved by a suitably designed hybrid system, whatever the size of the scale elasticity $\varepsilon$.

\section{Effects on Exit and Entry of Firms}

In modelling the performance of the two types of refunding mechanisms in the previous sections, we ignored potential impacts on exit and entry. A thorough analysis of entry and exit demands consideration of market structure and of the potential for firms to pass the subsidies/costs on to commodity prices. That is beyond the scope of our model (see Cato 2010, which focuses more on these issues). However, we have observed that a difference between a standard tax and a refunded fee is that the former generates public revenue, 
whereas the refunding systems are revenue neutral, as the emission tax (fee) collected by the fund is redistributed to the firms. A standard tax may lead to a situation where some firms are no longer able to cover their total costs for any output level, and thus it is profitmaximizing for them to close down production. Compared with a standard tax system, the refunding systems may prevent closures, and promote entry, as the firms receive an income from the reimbursement of emissions taxes. Hence, both OBR and EBR lead in principle to a lower degree of exit and a higher degree of entry, compared with a standard tax.

The crucial variable for the entry decision must be the profit per unit capital. According to Proposition 6, the system with lowest equilibrium output has the highest aggregate profit. Hence, if capital is positively correlated with output, the system with the lowest output per firm has the highest profit per unit of capital and provides the largest incentive for entry (or disincentive for exit). However, we cannot in general tell whether that is OBR or EBR; see Proposition 5.

Compared with no environmental policy, EBR encourages exit, because all firms are worse off (Proposition 7), whereas OBR encourages entry of firms with sufficiently low emissions per unit of output (Proposition 8). ${ }^{20}$

\section{Practical Considerations of the Norwegian and Swedish Systems}

In the previous sections, we have compared the tax systems assuming that the abatement target was the same across systems. In practice, OBR and EBR are likely to be used when political or practical conditions make a sufficiently high $t$ in a standard tax system impossible or undesirable. ${ }^{21}$ Thus, from a political viewpoint, the relevant comparison might be between a standard tax system with a low $t$, and thus a low abatement target, and OBR and EBR systems with a high(er) abatement target. In this case, production might still be higher under the OBR and EBR systems, but certainly there will be higher expenditures on abatement activities. As mentioned, higher production is often considered desirable by politicians in economies with excess labour capacity. The investments also can create employment and may speed up the development of the abatement industry through scale effects and learning by doing, possibly even creating export opportunities or other strategic advantages for domestic industry.

Table 1 summarizes a few key characteristics of the Norwegian and Swedish policy instruments that inspired this analysis. Although superficially similar, the two rebate schemes for $\mathrm{NO}_{\mathrm{x}}$ reduction have big differences. The Swedish system was introduced because Pigouvian taxes of a sufficiently high magnitude to incentivize abatement were judged impossible, for at least three reasons. First, the regulator wanted to target some (large), but not all, installations, and a tax for just large plants would have created an incentive to invest in small plants. Second, there could have been an incentive to invest abroad.

\footnotetext{
${ }^{20}$ In practice, the regulator in Sweden has taken pains to avoid entry into the rebating scheme by firms with zero emissions (such as using an electric technology to produce power) since they would take quickly a large share of refunds.

21 Politicians, who make many of the relevant decisions, rarely want output reduction in any sector. On the contrary, one of the main obstacles for any environmental policy is the threat to jobs. Although a reduction in jobs in some sectors might be part of an economically "optimal" strategy, it rarely goes over well with voters. Furthermore, the conditions under which the policy is optimal may not be met. This applies inter alia to cases where oligopoly exists or in small, open economies where there is a threat to competitiveness through foreign competitors that do not face environmental policies.
} 


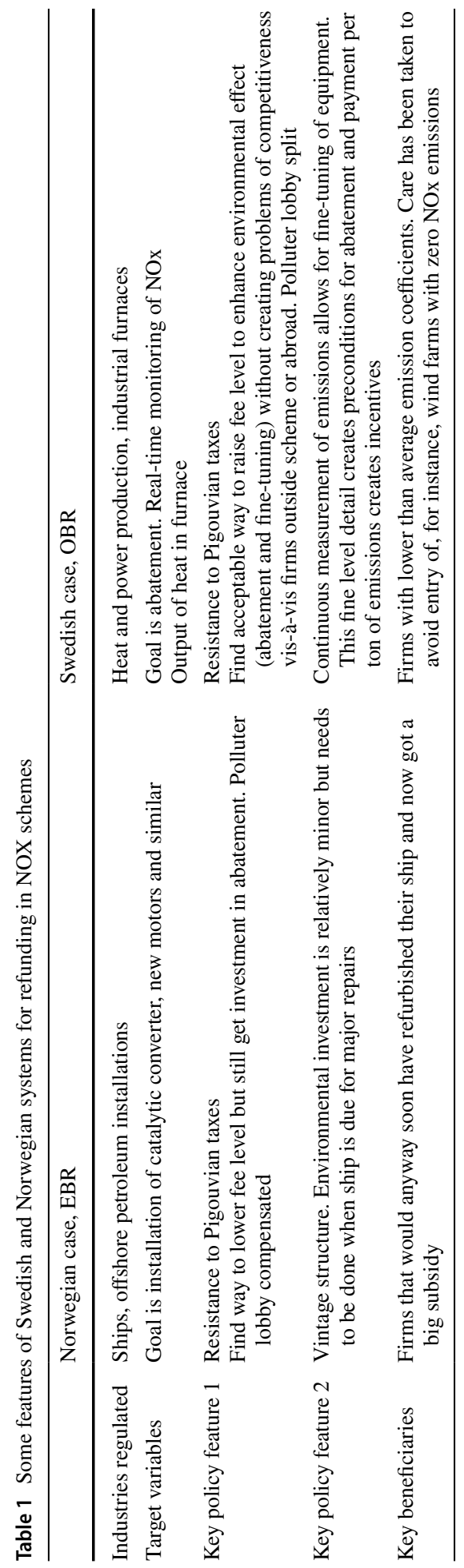


This would probably not have been a big problem for heat and power nor for the forest industry but could have been for some of the other industrial users. Third, lobbying from the polluters would have been too powerful. The OBR scheme split the lobby because half the firms (those with lower than average emission coefficients) earn net revenue. The scheme has even been able to expand the number of firms eligible and to increase the fee with little industry opposition. A key experience of this scheme was that actual measurement of emissions was crucial to fine tuning of equipment-otherwise, engineers do not know which parameters reduce emissions. A key challenge for OBR is to find a measure of output that is accepted. In this case, there was agreement on heat output at the furnace level as a fair and objective measure; see Fredriksson and Sterner (2005), Isaksson (2005), and Sterner and Isaksson (2006) for details.

The Norwegian EBR system, by contrast, concerns inter alia ships in very difficult marine environments, and real-time measurement from chimneys was deemed unrealistic. Hence the target is not abatement itself but verified installation of "abatement equipment" such as catalytic converters, improved motors, etc. Also, no easy measure of "output" is available. Hence the Norwegians eschewed the Swedish system and first legislated a pure tax. Because no measurement is available, the tax was levied based on assumed emission coefficients, which can be reduced through abatement technology investments. Obviously, the affected polluters complained over paying a tax, and a policy entrepreneur offered the government to run a scheme with a much lower fee that is then refunded to subsidize abatement. The fee for ships was set to $4 \mathrm{NOK} / \mathrm{kg} \mathrm{NO}_{\mathrm{x}}$, corresponding to $27 \%$ of the original pure tax, is in accordance with Proposition 2. See Hagem et al. (2014) for details. Key beneficiaries of the Norwegian system were firms that were due for major refurbishment, for which they now got a large subsidy. Key beneficiaries of the Swedish system were the firms with lowest emissions per unit output, which is in line with Proposition 8.

In the choice between the different tax systems, the differences in social welfare, profits, abatement and output are all important. In addition, there may be important administrative differences. For sectors producing homogeneous goods, output-based refunding systems may be relatively simple to design. However, output-based refunding can be controversial to operate when firms produce differentiated products and output is hard to measure, as for the Norwegian firms. Similarly, in our model we have assumed that expenditures on abatement technology are well-defined and easy to distinguish from other expenditures and investments of the firms. In practice, this usually will not be the case. Differences between the two systems regarding administrative complexity may thus be an important consideration in the choice between the two systems. This may explain the limited number of schemes observed and their variety. As mentioned, the French Taxe Parafiscale on $\mathrm{NO}_{\mathrm{x}}$ and various other air pollutants had features of both OBR and EBR, even if the latter dominated. Similarly, many examples in developing countries use a mix of principles to allocate the funds collected from environmental fees. Several North American schemes are primarily lump-sum per capita reallocations, but they also may contain elements of expenditurebased allocation.

\section{Concluding Remarks}

Policymakers often emphasize a number of aspects of environmental policy in addition to efficiency. Activity reductions in local industries, possible job losses, leakage effects (polluting industries relocating to other countries), and distributional concerns loom large. 
Hence the environmental policy instrument preferred by most economists, the Pigouvian tax, is seldom as popular as economists think it deserves to be. We have analysed two alternative mechanisms that imply refunding emission payments to polluting firms: outputbased refunding (OBR) and expenditure-based refunding (EBR). Our main findings are as follows.

Given a certain emissions target, the tax/fee level that ensures the target is met is lower in the standard tax system than in the OBR system, but it is even lower in the EBR system. These differences, in turn, lead to differences in the distribution of costs across firms. Both refunding mechanisms lead to cost-ineffective combinations of abatement technology and output reduction, with higher output and more abatement technology than is efficient from the viewpoint of a simple economic model. However, this effect may be seen as an advantage by policymakers if they seek to avoid activity reduction in the regulated sector.

Intuitively, one might expect that an EBR system would lead to higher investment in abatement equipment than an OBR system, while an OBR system should lead to higher output. We found that this is not a general result. Whether EBR or OBR causes a larger investment in abatement equipment depends on the firms' abatement functions and parameters of the model. We show that, given an aggregate emissions target, investment in abatement technology (and output) is highest under OBR if emissions are approximately proportional to output for the industry as whole. On the other hand, if emissions are proportional to an input, and output has decreasing returns to this input, the opposite may occur. There could also be complex knock-on effects on other industries, particularly if they have integrated supply chains or if only certain sectors have OBR or EBR.

An important difference between the two systems is in the regulator's need for information to regulate the systems effectively. All systems (including a regular tax) require information about firms' emissions. In addition, the OBR system requires information about output, which is usually available but in many cases may be open to manipulation (such as through transfer pricing if based on values, or by categorization if by physical dimensions). In the Swedish $\mathrm{NO}_{x}$ policy case, the physical heat and energy output of boilers was chosen as a readily verifiable and relevant measure. It is not unlikely that the lack of applications in other areas is due to the difficulty of using, for instance, gross sales values as a measure. The EBR system, on the other hand, demands knowledge about the firms' costs of purchasing and utilizing abatement technology. As a result of asymmetric information between the firms and the managers responsible for determining refunds, the firms may gain large informational rents by overstating the cost of the abatement technology. Recall here that emissions reductions often are a consequence of different types of commercially profitable projects, such as rebuilding engines for higher efficiency. Furthermore, in order to gain informational rent, the firms may not choose the most cost-effective abatement technology project, but instead may implement technologies where their private cost information advantage is the greatest. The EBR system will be very popular with firms planning for refurbishment or other investments for which they can get a subsidy. These are often firms with large current emissions. On the other hand, OBR will be very popular with firms that currently have very low emission intensity. There is evidence that the OBR system in Sweden has provided an incentive for technology development when it comes to catalytic conversion (Sterner and Turnheim 2006; Isaksson and Sterner 2009).

In this paper, we have mentioned various reasons why policymakers may prefer refund systems over a standard tax system. Although it is not efficient in a standard static sense, and although there are some political economy peculiarities, refunded emission taxes remain an interesting addition to the menu of policy instruments available, particularly for cases when it is not possible to implement a tax that is sufficiently high (but when it is possible to identify 
discrete abatement investments that are desirable). An area for future research is to analyse more specifically how the optimal choice of emission policy mechanisms depends on how policymakers emphasize various policy targets (e.g., emission reductions, industries' activity level, income distribution, diffusion of abatement technologies). In this context, the availability of many options, including refunding based on output, abatement technology or other considerations, and mixes of factors may well be perceived as advantageous. The choice of instrument design may depend on many factors of industry structure, measurement possibilities, monitoring ability and the characteristics of the production and abatement technologies. All this provides a rich field for future research.

Acknowledgements While carrying out this research Hagem and Hoel have been associated with CREE -Oslo Centre for Research on Environmentally friendly Energy. CREE is supported by the Research Council of Norway. Thomas Sterner was part-time funded by SSB. Funding from Mistra Carbon Exit is also gratefully acknowledged. We wish to thank three anonymous referees for very constructive comments. Valuable comments by Taran Fæhn, Jack Pezzey, Katrin Millock, Torbjørn Hægeland, Arvid Raknerud, and research assistance by Amie Svärd, are also gratefully acknowledged. We also thank Phillippe Bontems for insightful comments that led to a deeper analysis of mixed refunding in part 4 of the manuscript. Finally, we thank Bjart Holtsmark for great insights and good collaboration on related papers, and Co-Editor Carolyn Fischer for her special insights and level of help and engagement.

Funding Open Access funding provided by Statistics Norway.

Open Access This article is licensed under a Creative Commons Attribution 4.0 International License, which permits use, sharing, adaptation, distribution and reproduction in any medium or format, as long as you give appropriate credit to the original author(s) and the source, provide a link to the Creative Commons licence, and indicate if changes were made. The images or other third party material in this article are included in the article's Creative Commons licence, unless indicated otherwise in a credit line to the material. If material is not included in the article's Creative Commons licence and your intended use is not permitted by statutory regulation or exceeds the permitted use, you will need to obtain permission directly from the copyright holder. To view a copy of this licence, visit http://creativecommons.org/licenses/by/4.0/.

\section{Appendix 1: Interpretation of the Abatement Function a $(r, y)$}

For the sake of simplicity, we have omitted the subscript $i$ in this appendix. Output $q$ is given by an increasing and strictly concave production function of an input $v$ with price $p_{v}$, and emissions are a function of output as well as technology variable $y$ :

$$
\begin{gathered}
q=F(v), \\
e=e(q, y) .
\end{gathered}
$$

We assume $e_{q}^{\prime}>0, e_{y}^{\prime}<0$, and $e_{y y}^{\prime \prime}>0$. In other words, we assume that emissions are increasing with production, and that reducing emissions via abatement technologies becomes increasingly difficult.

With this setup, the cost function $c(q)$ is $c(q)=p_{v} F^{-1}(q)$, and $c^{\prime \prime}>0$ for $F^{\prime \prime}<0$. Without any environmental policy, $q^{0}$ and $e^{0}$ are given by

$$
\begin{gathered}
c^{\prime}\left(q^{0}\right)=p, \\
e^{0}=e\left(q^{0}, 0\right) .
\end{gathered}
$$

The abatement function $a(r, y)$ is given by 


$$
a(r, y)=e^{0}-e\left(q^{0}-r, y\right)
$$

with properties

$$
\begin{aligned}
& a_{r}^{\prime}=e_{q}^{\prime}>0 \\
& a_{y}^{\prime}=-e_{y}^{\prime}>0 \\
& a_{r r}^{\prime}=-e_{q q}^{\prime \prime} \\
& a_{y y}^{\prime \prime}=-e_{y y}^{\prime \prime}<0 \\
& a_{r y}^{\prime \prime}=e_{q y}^{\prime \prime} .
\end{aligned}
$$

In the main text we assumed that that $r$ and $y$ are normal inputs in the production of $a$ (which requires that $a_{r}^{\prime} / a_{y}^{\prime}$ is declining in $r$ and increasing in $y$ ). For our results to hold, we only need the following slightly weaker condition for the cross derivative $a_{r y}^{\prime \prime}=G_{q y}^{\prime \prime}$ :

$$
a_{r y}^{\prime \prime}>\operatorname{Min}\left[\frac{a_{r}^{\prime}}{a_{y}^{\prime}} a_{y y}^{\prime \prime}, \frac{a_{y}^{\prime}}{a_{r}^{\prime}}\left(a_{r r}^{\prime \prime}-\frac{c^{\prime \prime}}{t}\right)\right] .
$$

Without the term with $c^{\prime \prime} / t$ in (34), this condition is equivalent to assuming that $r$ and $y$ are normal inputs in the production of $a$. Since the term $-c^{\prime \prime} / t$ is negative, condition (34) is weaker than assuming normal inputs.

An important special case is that emissions are proportional to output, i.e. $e=q g(y)$ with $g^{\prime}<0$ and $g^{\prime \prime}>0$. For this case we have

$$
\begin{aligned}
& a_{r}^{\prime}=g(y)>0 \\
& a_{y}^{\prime}=-q g^{\prime}(y)>0 \\
& a_{r r}^{\prime}=0 \\
& a_{y y}^{\prime \prime}=-q g^{\prime \prime}(y)<0 \\
& a_{r y}^{\prime \prime}=g^{\prime}(y)<0 .
\end{aligned}
$$

The condition (34) for the cross derivatve $a_{r y}^{\prime \prime}=g^{\prime}(y)$ is in this case.

$$
g^{\prime}>\operatorname{Min}\left[\frac{g g^{\prime \prime}}{g^{\prime}}, \frac{c^{\prime \prime} q g^{\prime}}{t g}\right] \text {. }
$$

which will hold for $c^{\prime \prime}$ and $g^{\prime \prime}$ sufficiently large (in spite of $r$ and $y$ not both being normal inputs in this case).

\section{Appendix 2: Characterisation of Equilibrium Outcomes in the Standard Tax System}

We derive the second-order conditions for global profit maximum and show how the equilibrium outcomes change with $t, m$, and $p$ in the ST system. To simplify notation, we skip the subscript $i$ in this appendix.

The optimization problem gives us the following profit function: 


$$
\pi(p, t, m)=\operatorname{Max}_{r, y}\left[p\left(q^{0}-r\right)-c\left(q^{0}-r\right)-t\left(e^{0}-a(r, y)\right)-m y\right] .
$$

We know that profit functions of this type are strictly convex. Moreover, from the envelope theorem we have

$$
\begin{gathered}
\pi_{p}^{\prime}=q^{0}-r \\
\pi_{t}^{\prime}=a-e^{0} \\
\pi_{m}^{\prime}=-y .
\end{gathered}
$$

Using the convexity of the profit function it follows that

$$
\begin{aligned}
& \frac{\partial r}{\partial p}=-\pi_{p p}^{\prime \prime}<0 \\
& \frac{\partial a}{\partial t}=\pi_{t t}^{\prime \prime}>0 \\
& \frac{\partial y}{\partial m}=-\pi_{m m}^{\prime \prime}<0 \\
& \frac{\partial r}{\partial t}=-\frac{\partial a}{\partial p}=-\pi_{t p}^{\prime \prime} \\
& \frac{\partial a}{\partial m}=-\frac{\partial y}{\partial t}=\pi_{t m}^{\prime \prime} .
\end{aligned}
$$

To find the sign of the last two derivatives, we use the first order conditions of the maximization problem:

$$
\begin{aligned}
-p+c^{\prime}\left(q^{0}-r\right)+t a_{r}^{\prime}(r, y) & =0 \\
t a_{y}^{\prime}(r, y)-m & =0 .
\end{aligned}
$$

Differentiating gives

$$
\frac{\partial r}{\partial t}=\frac{1}{D}\left[a_{y}^{\prime} a_{r y}^{\prime \prime}-a_{r}^{\prime} a_{y y}^{\prime \prime}\right]
$$

and

$$
\frac{\partial y}{\partial t}=\frac{1}{D}\left[a_{r}^{\prime} a_{r y}^{\prime \prime}-a_{y}^{\prime}\left(a_{r r}^{\prime \prime}-\frac{c^{\prime \prime}}{t}\right)\right],
$$

where

$$
D=-c^{\prime \prime} a_{y y}^{\prime \prime}+t\left[a_{r r}^{\prime \prime} a_{y y}^{\prime \prime}-\left(a_{r y}^{\prime \prime}\right)^{2}\right]>0
$$

due to the second order conditions for the profit maximization problem.

Using the condition (34) from Appendix 1 it follows that the two derivatives above are positive. From (39) it therefore follows that $\partial a / \partial p=-\partial r / \partial t<0$ and $\partial a / \partial m=-\partial y / \partial t<0$.

Hence, this proves Proposition 1 as a given rebate $(b)$ per unit production under the OBR corresponds to an increase in $p$ ( $p$ is replaced by $p+b$ ) under the ST system [see Eqs. (7) and (12)], and a given subsidy $(s)$ under the EBR corresponds to a decrease in $m$ ( $m$ is replaced by $m-s$ ) under the ST system [see Eqs. (7) and (16)]. 


\section{References}

Bernard AL, Fischer C, Fox AK (2007) Is there rationale for output-based rebating of environmental levies? Resour Energy Econ 29(2):83-101

Bontems P (2017) Refunding emissions taxes: the case for a three-part policy, TSE working papers 17-832. Toulouse School of Economics (TSE)

Cato S (2010) Emission taxes and optimal refunding schemes with endogenous market structure. Environ Resour Econ 46(3):275-280

Coria J (2009) Taxes, permits, and the diffusion of a new technology. Resour Energy Econ 31(4):249-271

Criqui P, Jaccard M, Sterner T (2019) Carbon taxation: a tale of three countries. Sustainability 11:6280

Edwards TH, Hutton JP (2001) Allocation of carbon permits within a country: a general equilibrium analysis of the United Kingdom. Energy Econ 23(4):371-386

Felder S, Schleiniger R (2002) Environmental tax reform: efficiency and political feasibility. Ecol Econ 42(1-2):107-116

Fischer C (2001) Rebating environmental policy revenues: output-based allocations and tradable performance standards. Discussion paper 01-22, Resources for the Future, Washington, DC

Fischer C (2011) Market power and output-based refunding of environmental policy revenues. Resour Energy Econ 33:212-230

Fischer C, Fox AK (2007) Output-based allocation of emissions permits for mitigating tax and trade interactions. Land Econ 83(4):575-599

Fischer C, Preonas L (2010) Combining policies for renewable energy: is the whole less than the sum of its parts? Resource for the future discussion paper no. 10-19. SSRN: https://ssrn.com/abstr act $=1569634$. http://dx.doi.org/10.2139/ssrn.1569634

Fischer C, Reins L, Burtraw D, Langlet D, Lofgren A, Mehling M, Weishaar S, Zetterberg L, van Asselt $\mathrm{H}$, Kulovesi K (2020) The legal and economic case for an auction reserve price in the EU emissions trading system. Columbia J Eur Law (forthcoming)

Fredriksson PG, Sterner T (2005) The political economy of refunded emissions payments programs. Econ Lett 87(1):113-119

Fullerton D (1997) Environmental levies and distortionary taxation: comment. Am Econ Rev 87(1):245-251

Fullerton D, Mohr R (2003) Suggested subsidies are sub-optimal unless combined with an output tax. B.E. J Econ Anal Policy 2(1):1097

Gersbach H, Requate T (2004) Emission taxes and optimal refunding schemes. J Public Econ 88(3):713-725

Goulder LH, Parry IWH, Williams RC, Burtraw D (1999) The cost-effectiveness of alternative instruments for environmental protection in a second-best setting. J Public Econ 72(3):329-360

Hagem C, Holtsmark B, Sterner T (2014) NOx-fondet gir ikke en kostnadseffektiv løsning. Samfunnsøkonomen nr. 5

Hepburn CJ, Quah JKH, Ritz RA (2013) Emissions trading with profit-neutral permit allocations. J Public Econ 98:85-99

Hoel M (1991) Global environmental problems: the effects of unilateral actions taken by one country. J Environ Econ Manag 20(1):55-70

Isaksson LH (2005) Abatement costs in response to the swedish charge on nitrogen oxide emissions. J Environ Econ Manag 50(1):102-120

Isaksson L, Sterner T (2009) Innovation effects of the Swedish NOX charge, OECD FORUM ON ECOINNOVATION. COM/ENV/EPOC/CTPA/CFA(2009)8/FINAL OECD, Paris

Jaffe A, Newell R, Stavins R (2002) Environmental policy and technological change. Environ Resour Econ 22(1):41-70

Johnson KC (2006) An effective regulatory instrument for cost-constrained environmental policy. Energy Policy 34(18):3965-3976

Kallbekken S, Kroll S, Cherry TL (2011) Do you not like pigou, or do you not understand him? Tax aversion and revenue recycling in the lab. J Environ Econ Manag 62(1):53-64

Kolstad CD (2000) Environmental economics. Oxford University Press, New York

Löschel A (2002) Technological change in economic models of environmental policy: a survey. Ecol Econ 43(2-3):105-126

Meunier G, Montero JP, Ponssard JP (2018) Output-based allocations in pollution markets with uncertainty and self-selection. J Environ Econ Manag 92:832-851

Millock K, Nauges C (2006) Ex post evaluation of an earmarked tax on air pollution. Land Econo 82(1):68-84

Millock K, Nauges C, Sterner T (2004) Environmental taxes: a comparison of French and Swedish experience from taxes on industrial air pollution. CESifo DICE Rep 1:30-34 
Nicolai J-P (2015) Emission reductions and profit-neutral permit allocations. Working paper 15/224, CER-ETH-Center for Economic Research at ETH Zürich

Parry IWH, Norregard J, Heine D (2012) Environmental tax reform: principles from theory and practice. Annu Rev of Resour Econ 4:101-125

Pezzey JCV (1992) The symmetry between controlling pollution by price and controlling it by quantity. Can J Econ 25:983-991

Pezzey JCV (2003) Emission taxes and tradeable permits: a comparison of views on long run efficiency. Environ Resour Econ 26(2):329-342

Requate T (2005) Dynamic incentives by environmental policy instruments: a survey. Ecol Econ 54(2-3):175-195

Sterner T, Coria J (2012) Policy instruments for environmental and natural resource management. RFF Press, New York

Sterner T, Isaksson LH (2006) Refunded emission payments theory, distribution of costs, and Swedish experience of NOx abatement. Ecol Econ 57(1):93-106

Sterner T, Turnheim B (2006) Innovation and diffusion of environmental technology: industrial NOx abatement in Sweden under refunded emission payments. Ecol Econ 68(12):2996-3006

Svendsen GT, Daugbjerg C, Hjollund L, Branth Pedersen A (2001) Consumers, industrialists and the political economy of green taxation: CO2 taxation in OECD. Energy Policy 29(6):489-497

Walls M, Palmer K (2001) Upstream pollution, downstream waste disposal, and the design of comprehensive environmental policies. J Environ Econ Manag 41(1):94-108

Publisher's Note Springer Nature remains neutral with regard to jurisdictional claims in published maps and institutional affiliations. 